\title{
STRATEGIES TO FLIP A CLASSROOM: LESSONS LEARNT FROM A JOINT-UNIVERSITY PROJECT
}

\author{
Paul Lam, Carmen K. M. Lau and Chi Him Chan \\ The Chinese University of Hong Kong, Hong Kong
}

\begin{abstract}
The flipped classroom approach is widely regarded to be able to enhance teaching and learning. Despite its many advantages, it is still in the early stage of implementation in Hong Kong. This may be due to the potential challenges such as learners' limited participation and adaptation problems. The purpose of this article is to discuss the challenges based on Brame's (2013) four key elements of the flipped classroom exposure, incentive, assess, and activities. Particularly, we put emphasis on how teachers from Hong Kong higher education address the four aspects of challenges in their flipped classroom planning and design. Teachers of twenty-six courses in five universities in Hong Kong were invited to complete a teaching profile for their coming flipped courses which they were asked to elaborate their teaching goals and how they would execute the course. The teaching profiles revealed that the teachers devised a wealth of different strategies in implementing flipped classroom. We generalized their careful planning into eleven tips that can be seen as the collective wisdom of the teachers, as well as potential solutions to the flipped classroom challenges. This article summarizes the first phase of our study that eventually will examine the success factors of the flipped classroom approach in Hong Kong higher education.
\end{abstract}

\section{KEYWORDS}

Flipped Classroom, Pedagogical Issues, Teaching/Learning Strategies, Improving Classroom Teaching, Tertiary Education

\section{INTRODUCTION}

The flipped classroom is an idea to move lectures out of the classroom and bring activities such as projects, discussions, and presentations into the classroom. Because it reverses the traditional classroom, it is called "flipped" or "inverted" classroom. The basic principle of the flipped classroom approach is to remove unilateral information presenting activities such as traditional lectures from the classroom, so that classroom time is freed for activities that focus on assimilating or applying knowledge. Under this principle, content and form of delivery of both in-class and out-of-class activities can be varied. Therefore, there is no single model of flipping 
IADIS International Journal on WWW/Internet

the classroom (Sams, 2011). For example, lectures can be delivered as audio or audio-visual materials through distance learning technologies such as multimedia or online delivery, and activities of different teaching styles or the use of active learning strategies that focus more on application of knowledge can be applied in classroom time according to teaching needs (Baker, 2000; Lage et al., 2000). Teachers are given the flexibility to design their courses according to their students' need. This approach, compared with the traditional instruction method, has numerous advantages, including enhancing students' knowledge, skills, and learning behavior.

Statistical evidence shows that the flipped classroom approach enhances students' learning outcome (Davies et al., 2013; Mason et al., 2013; McGivney-Burelle and Xue, 2013; Bhagat et al., 2016). Students in the flipped classroom perform better than their traditional classroom counterparts in their examinations. Such an enhancement is especially notable in the weaker student group (Bhagat et al., 2016). Three of the advantages of the flipped classroom approach contribute to this enhancement.

First, the flipped classroom approach promotes active learning strategies that can motivate students to learn (Bhagat et al., 2016). Active learning is an instructional method that engages students in the learning process. In this method, students undertake and cognitively engage in different meaningful learning activities (Chen et al., 2018). Engaging students in the learning process can enhance their conceptual understanding (Prince, 2004). Students can also experience higher levels of relatedness by being active participants in the course (Abeysekera and Dawson, 2014). The flipped classroom introduces different kinds of learning activities into the classroom, thus agrees with the active learning principle (Gannod et al., 2008).

The flipped classroom approach maximizes the benefits of active learning by providing a constructive learning environment. The flipped classroom combines video lectures and hands-on classroom experience from different in-class activities and creates a constructive learning environment. A constructive learning environment is a multisensorial environment that provides information for students (Gannod et al., 2008). It allows students to construct their knowledge by actively exploring different learning materials and participating in different activities (Gannod et al., 2008). Research also proves that students learn better by receiving information from more than one channel (Bhagat et al., 2016).

Second, the flipped classroom approach allows more interaction. All students receive immediate feedback from teachers, and interaction among students also increases because discussions are encouraged. In a flipped classroom, weaker students receive more attention from teachers and assistance from their peers, so their performance is enhanced (Bhagat et al., 2016; Gouia and Gunn, 2016). Students in middle level interact with the advanced students, argue with their peers, and assist weaker students. They can reinforce their understanding and consolidate their knowledge by explaining concepts to each other, and they can learn from their peers, too (Baker, 2000; Gannod et al., 2008; Gouia and Gunn, 2016). Passive students also have an opportunity to talk to teachers. On the other side of the coin, teachers also have more chance to engage their students, which is more rewarding than repeating lectures.

Third, teachers can focus on students' individual needs in class time. Students can re-watch lecture videos according to their own needs so that teachers do not need to explain the learning materials in class. The class time can be utilized to provide different learning activities to cater to students' different needs. The differentiated instructional approach allows students to work at their own pace according to their abilities (Davies et al., 2013). In a flipped class, while weaker students focus on elementary problems under teachers' guidance, advanced students can work on in-depth problems and develop a higher understanding (Gouia and Gunn, 2016). Also, 
teachers use class time more effectively, so often, teachers can cover more topics (Gannod et al., 2008; Mason et al., 2013).

The flipped classroom approach can be associated with learning of various generic skills too. Brame suggests that the in-class time should be spent on work that demands higher forms of cognitive skills, such as analysis, synthesis, and application of knowledge (Brame, 2013). Therefore, students' skill in problem-solving and applying knowledge into other scenarios is improved (Persky and McLaughlin, 2017; White, 2017). Students are also more confident in their learning skills and their abilities in applying knowledge (Fautch, 2015; Cheng et al., 2017). Moreover, in-class activities that require students to interact with each other also enhance students' skills in communication, collaborative, and teamwork (Persky and McLaughlin, 2017).

Finally, the flipped classroom model gives students greater control over their learning progress (Gannod et al., 2008) and it may lead to better learning attitudes and behaviors. In a flipped classroom, students get access to pre-class materials whenever they need. They can also re-watch, pause, or rewind videos according to their own needs. Therefore, students enjoy a higher degree of flexibility and they are able to learn at their own pace. It cultivates a greater sense of responsibility for their learning and encourages them to become self-learners (Baker, 2000; Lage et al., 2000; Mason et al., 2013). Regular test on pre-class exposure is an essential component in the flipped classroom, and this encourages students to develop self-regulated learning behaviors (Baker, 2000; Moraros et al., 2015; Persky and McLaughlin, 2017). The flipped classroom also enhances motivation for learning and engagement as more activities introduced into the classroom (Khanova et al., 2015; Bhagat et al., 2016). In general, students are more satisfied with this approach of learning than the traditional one (Davies et al., 2013; Mason et al., 2013; Fautch, 2015; Gilboy et al., 2015).

According to Gökçe Akçayır and Murat Akçayır (2018), the number of research articles on the flipped classroom steadily increased after 2012, with $79 \%$ of those studies conducted between 2015 and 2016. With growing research interest and efforts in the pedagogy, various challenges on its implementation were discovered. One of the most frequent challenges discovered was limited student preparation before class. Other challenges included students' adaptation problems caused by their anxiousness and resistance, teachers' unwillingness to participate, and a lack of school support or technical support (Akçayır and Akçayır, 2018).

This article examines and categorizes the abovementioned challenges according to a framework based on four key elements suggested by Brame (2013). In addition, we explore how university teachers in Hong Kong designed their flipped classrooms in response to the four areas of challenges through a cross-university study conducted in 2018. Teachers of twenty-six courses in five universities in Hong Kong were invited to complete a teaching profile on how they would design their flipped courses. By analyzing these teaching profiles, we discovered eleven tips on the level of course design which might be able to meet the challenges.

\section{CHALlENGES}

In her guide to flipping the classroom, Brame identifies four key elements in the flipped classroom, namely "exposure", "incentive", "assess", and "activities". These key elements should be well thought out before course delivery to guarantee its success. 
IADIS International Journal on WWW/Internet

\subsection{Exposure}

"Exposure" implies the opportunity for students to gain first exposure prior to class. In a flipped classroom, learning materials are provided for students to study before class so that they obtain basic knowledge and skills to participate in high cognitive activities during class (Brame, 2013).

Although Brame suggests that pre-class exposure does not need to be high-tech, most teachers still choose to deliver learning materials in the form of videos (Akçayır and Akçayır, 2018). But delivering lecture through videos poses a frequent challenge - how to ensure its quality? Teachers face numerous difficulties in making good videos as they do not have the relevant skills or resources (Snowden, 2012). Even for the teachers who have the corresponding skills, creating videos is time-consuming (Herreid and Schiller, 2013). Nevertheless, teachers are hesitant to use videos provided by others because they believe that students strongly prefer teachers to make the videos themselves (Gouia and Gunn, 2016). The unavailability of high-quality videos could undermine students' understanding of the contents.

Moreover, the length of a video also affects students' willingness to view. The longer the video, the fewer the view counts (Akçayır and Akçayır, 2018). Students are unwilling to view long lectures which exceed an hour because they cannot finish the lectures in a single seating (Moraros et al., 2015). The form and medium of delivering pre-class exposure play a crucial role in students' perception of the teaching approach.

Besides the form and medium, students sometimes need additional assistance for pre-class exposure. Some students report that they are unable to get help, for they cannot ask questions immediately when they are viewing pre-class materials (Fautch, 2015; Chen et al., 2015). Researches also suggest that clear guidelines or instruction are crucial for pre-class learning (Wanner and Palmer, 2015).

\subsection{Incentive}

"Incentive" is a "pull" factor that motivates students to participate in the flipped classroom learning processes. Comparing to a traditional classroom, the workload of students in a flipped classroom increases because they are required to prepare for the class and participate in class actively (Gannod et al., 2008; Khanova et al., 2015). Therefore, some additional incentives would be crucial for motivating students to participate in the flipped classroom learning processes.

There are two types of incentive for learning. Extrinsic incentive refers to individuals engaging in learning because it leads to separable outcomes. Marks and grades are examples of extrinsic incentive. Intrinsic incentive refers to individuals engaging in learning because it is inherently interesting and enjoyable (Abeysekera and Dawson, 2014). Brame suggests that tasks should be set to indicate that students have finished their preparation before they attend class, and extrinsic incentive can be provided by assigning scores to motivate students to finish these tasks (Brame, 2013). Apart from the extrinsic incentive of giving scores, intrinsic incentive such as promoting students' acceptance of the flipped classroom approach is also essential in the "incentive" element. Previous studies show that some students do not participate in the flipped classroom because they are anxious about the flipped classroom approach. They are uncertain about what the flipped classroom may entail. Some students do not view it as useful comparing to traditional lectures (Akçayır and Akçayır, 2018). Moreover, the flipped classroom approach may disfavor less active students (Strayer, 2007). They may find themselves in an unsafe 


\section{STRATEGIES TO FLIP A CLASSROOM: LESSONS LEARNT FROM A JOINT-UNIVERSITY}

situation where they need to participate actively in class instead of passively listening to lectures as in the traditional lecturing approach (Chen et al., 2014). Worse still, they may even think that the flipped learning environment is unfair or unbearable. All of these factors contribute to students' resistance to the flipped classroom approach (Akçayır and Akçayır, 2018).

\subsection{Assess}

“Assess" is a mechanism to assess students' understanding. The assessment on pre-class exposure aims mainly at evaluating how well students understand the materials. If teachers grade the content of these assessments, they can identify areas that students are struggling with so that they can tailor in-class activities according to students' needs (Brame, 2013). If, on the contrary, teachers grade these assessments for completion, the low-stake grading approach might be able to motivate students to finish the assessments, and these assessments can serve as evidence of students' preparation. (Kim et al., 2014).

Challenges usually occur when using the assessment to check students' preparation. Although some teachers assign quizzes at the beginning of a class, it is still difficult to ensure that students study the pre-class materials thoroughly. Fautch (2015) reported that formative assessment that graded upon completion is difficult to hold students accountable for their preparation, because the questions are usually not hard enough and the grade is insignificant. For the open-end questions, students often make up answers or comments without watching the pre-class exposure materials for getting the participation marks with the least effort (Kim et al., 2014). In addition, online quizzes are vulnerable to students' inappropriate behaviors. Students might guess all the choices of a multiple-choice question until getting the right answer or search through the material to find correct answers just to complete the assessments (Koh et al., 2018). Students might exploit the advantage to finish the assessments without learning from the materials.

\subsection{Activities}

The "Activities" component means in-class activities. Students learn basic knowledge outside the classroom. Therefore, different activities can be introduced into the classroom to promote deeper learning and improve their skills. Brame provides a board range of activities and advises teachers to make their choice according to the learning objective of their class and the culture of their discipline (Brame, 2013).

Planning activities can be challenging for teachers. If teachers fail to plan meaningful activities and guide students through these activities, students may withdraw from the class. Strayer (2007) provides an example of this. In Strayer's class, too many types of activities with different goals were given to his students. The students felt that it was difficult for them to meet the expectation of each activity and to navigate the expectation for the whole class, and therefore they "were 'lost' by the end" (Strayer, 2007, p. 160). Besides the number of types of in-class activities, the content of in-class activities can also pose a challenge. In-class activities are prone to three risks: repeating the content of pre-class exposure, introducing entirely new materials, and without connection to the pre-class exposure (Khanova et al., 2015). The lack of cohesive alignment between pre-class exposure, in-class activities, and the learning objectives can distract students' from participating in the activities (Kim et al., 2014; Persky and McLaughlin, 2017). 
IADIS International Journal on WWW/Internet

Another challenge for teachers is the need to pay more effort in enhancing interaction. One of the significant benefits of the flipped classroom is the increased chances for all sorts of interactions (between teachers and students and among students themselves). However, we should not think that interactions come automatically after adopting the flipped classroom approach. It requires teachers' ability to facilitate and administrate the class (Kim et al., 2014), and their ability to design interactive in-class activities. Moreover, facilitating interactive activities is more challenging in classes of large size (Gannod et al., 2008; Kim et al., 2014). Failing to build interaction with students has detrimental effects. Without interactive activities to engage students, students are tempted to work on tasks unrelated to the class and the class would be disrupted (Strayer, 2007).

To conclude, various challenges may arise in these key elements and they can hamper the successful implementation of a flipped classroom. However, these challenges can be met by careful planning of the course. By examining the course design of teachers from Hong Kong higher education institutions, this article tries to extract some tips that may be able to meet these potential challenges.

\section{METHOD}

\subsection{Participants}

Five universities (The Chinese University of Hong Kong, City University of Hong Kong, The Education University of Hong Kong, Hong Kong Baptist University, and The Hong Kong Polytechnic University) are engaged in a collaborative project (https://www.flippedclasshk.net/) to support teachers to use the innovative pedagogy. The project invited teachers who intended to implement the flipped classroom approach in their courses to participate in the first phase of the project. Teachers of twenty-six courses from various fields of study were recruited. The courses that they intended to flip were also offered to students of different levels. Demographics of the courses can be seen in the table below:

Table 1. Demography of the courses participated

\begin{tabular}{|l|l|l|l|}
\hline Level & No. & Field of Study & No. \\
\hline Courses for undergraduates & 23 & Arts & 1 \\
\hdashline & & Business and & \\
Courses for graduates & 3 & Administration & 5 \\
\hline & & Education & 2 \\
& & Engineering & 2 \\
& & Textile & 1 \\
\hline & & Law & 1 \\
\hline & & Nursing & 2 \\
\hline & & Science & 8 \\
\hline & & Social Science & 4 \\
\hline Total No. of Courses & 26 & & 26 \\
\hline
\end{tabular}




\subsection{Procedures}

The teachers were asked to complete a teaching profile before the semester began. The teaching profile was divided into two parts, the first on basic information of the course, and the second on course design. A sample of the teaching profile is in the appendix.

Basic information of the course included course name and code, its date, time, venue, and estimated number of students. This information helped us identify the size of each class, the level of targeted students, and the field of study of each course.

Questions on the course design are closely related to Brame's framework. Teachers were asked why they chose to implement the flipped classroom approach in their course and what goals they aimed to achieve. There were also questions about activities before class (exposure), ways to encourage students to complete the activities (incentive), activities during class and activities after class (activities), and assessment design (assess). Some teachers also wrote down their concerns regarding related issues in their teaching profile. The course design ideas collected in this part provided the data which is the collective wisdom of our teachers in implementing the innovative pedagogy.

\section{RESULTS}

From the teaching profiles, we can see that the teachers devised different measures to avoid the failure of their flipped classes. Through examining these measures, we extracted and generalized eleven tips that may be useful in meeting the challenges stated above. These tips are organized according to the four key elements and presented as follows.

\subsection{Exposure}

\subsubsection{Ensuring Video Quality and Using a Variety of Media}

Videos were still the most common type of medium in delivering pre-class exposure, as seen from the teaching profiles. For some teachers, however, making good quality videos remained a challenge. Two teachers explicitly stated that they would incorporate existing videos provided by others into their courses. Existing video lectures, such as Khan Academy or TED talks, are proven to be useful in minimizing boredom and distraction (Gilboy et al., 2015). Many publishers have also developed recorded videos with good quality and suitable duration (McGivney-Burelle and Xue, 2013). Using these videos can ensure the quality of pre-class exposure material and reduce teachers' burden on producing material.

We found that the teachers also employed a variety of media to deliver pre-class exposure in order to enrich students' learning environment. Pre-class readings and documents were assigned to students not only in text form but also as digital documents or websites. Some courses required students to search for texts they needed in the web by themselves. One course stressed the use of various formats in delivering pre-class exposure, including text, video, audio, and multimedia. Other types of pre-class exposure included animation, VR trip to a specific site, or visits to the showroom of famous brands. As stated, the combination of different learning materials and learning activities can provide a constructive learning environment for students (Gannod et al., 2008). In addition, the wide array of media types enables easier pre-class exposure (Kim et al., 2014) and enhances students' learning interest. 
IADIS International Journal on WWW/Internet

\subsubsection{Offering Additional Assistance to Students}

A persistent problem in the flipped classroom approach is that students cannot receive immediate responses when they have questions on the pre-class exposure materials (Fautch, 2015; Chen et al., 2015). Previous flipped classes encourage students to write down their questions and save them for lectures (Fautch, 2015). With the help of online discussion forums, students can raise questions whenever they need help, and teachers can offer instant feedback and immediate assistance to students by text message (Fautch, 2015). Most of the teachers in our project utilized the online discussion forum in the learning management software provided by their respective universities, such as FutureLearn, Moodle, and Canvas. One course even provided a discussion forum that allowed students to discuss with previous students of the course. These discussion forums enabled students to raise questions or discuss with each other even when they were out of class.

Besides, guiding questions would be useful to enhance students' understanding of the materials. Guiding question, if well-designed, can help students review learning contents, stimulate critical thinking, thus having a positive effect on learning performance (Thai et al., 2017). Well-designed questions can guide students to understand the pre-class exposure materials, thus reducing students' questions. Two courses provided guiding questions with some text-based materials to students as pre-class exposure, and both courses had discussions on preclass exposure material as their in-class activities.

\subsection{Incentive}

\subsubsection{Giving Score as an Incentive}

Incentives are necessary to motivate students to participate in a flipped classroom. A score is a strong extrinsic incentive for students (Brame, 2013). Most teachers chose to score the tasks relating to pre-class exposure for the final grade of their course. In fourteen courses that provided a detailed assessment scheme, eleven indicated that some score between $5 \%$ and $20 \%$ of final grade were assigned to tasks related to pre-class exposure. The other three courses listed the tasks relating to pre-class exposure as parts of "continuous assessment" that occupied between $30 \%$ and $50 \%$ of the final grade. In addition to directly assigning grades to tasks, teachers also incorporated the content of pre-class exposure material into the mid-term and final examination. One teacher decided to give bonus scores as an incentive, but no details on the arrangement of bonus marks were provided. Teachers believed that score is a common incentive for students to participate in any learning activities.

\subsubsection{Increasing Students' Acceptance of the Flipped Classroom}

Students' resistance to the flipped classroom approach posed a great challenge to their incentive, so it is crucial to reduce their resistance. The teachers in our project try to increase students' acceptance by explaining the advantages of the flipped classroom approach. Three teachers stimulated students' incentive by explaining the advantages of the flipped classroom and the usefulness of pre-class preparation to students. They explained to students that students can learn at their own pace, thus enhancing their autonomy. In a biology course, the teacher explained to his students that both understandings of the concepts and adequate training on the laboratory skills were important for experiment results, so students must acquire knowledge by watching pre-class exposure before class and do experiments during class time. For courses that 
had discussion activities, teachers explained to students that it would be easier for them to engage in in-class discussions with preparation before class. It is believed that if students realize that the flipped classroom can satisfy their needs for autonomy, their intrinsic incentive in learning can be facilitated (Abeysekera and Dawson, 2014). Nevertheless, not all teachers thought the buy-in process is necessary as they regarded that most students already accepted the flipped mode of learning because of previous experiences.

\subsection{Assess}

Assessment in the flipped classroom should aim at assessing students' understanding. The assessment result can demonstrate students' weakness, and teachers can tailor their in-class activities to focus on the students' need. Ideally, this assessment process can further improve their understanding. However, the teachers in our project seldom explored this aim of assessment. Instead, they emphasized the use of different assessment tasks to check students' preparation. Such an emphasis might be because they regard the need to ensure students' preparation as one of the most serious challenges.

\subsubsection{Assigning Pre-class Tasks}

Regarding the difficulty of ensuring students preparation, most courses required students to finish a variety of tasks before class. While those tasks mainly included multiple-choice questions and online quizzes, they were designed to ensure that students had studied the material thoroughly. For example, questions on pre-class exposure were made to cover more contents of the materials. Many of these tasks merely required students' completion. On the other hand, some courses required students to finish worksheets, write summaries, submit comments, or raise discussion questions as pre-class tasks while marks were allocated in a more stringent manner based on performance. These tasks reduce the likelihood that students exploit the advantage to finish the task without studying the pre-class exposure materials.

\subsubsection{Assessing Students through In-Class Activities}

Different kinds of in-class activities can also help check students' preparation before class. Four teachers stated that they would ask questions in class occasionally to check if students had prepared for class. Besides, students were required to finish tests or online quizzes in class. Six courses set quizzes in their classes by using different kinds of student response systems. These assessments were designed to be based on pre-class exposure. In-class discussions were also arranged on the basis of pre-class exposure. Students' preparation could be checked by observing students' participation in discussions.

\subsubsection{Designing Assessment that Connects to Pre-class and In-class Activities}

Teachers can also check students' preparation before class by building a strong connection between pre-class exposure, in-class activities, and assessments. Two courses connected students' preparation for the class to students' performance in in-class activities, which was part of the assessment. In the first course, students were required to watch a 10-15 minutes video clip on teaching and write a lesson plan on the clip with possible ways of improvement as pre-class exposure. In the class, students discussed each other's plan, presented their findings, modified their plan based on their findings, and performed trial teaching. They were required to design a worksheet after the class. All tasks above would contribute to their final grade. In 
another course, students were required to read the assigned texts, search additional sources from the web, and have a showroom visit as pre-class exposure. In the class, students worked in groups to brainstorm and present a tactical marketing plan on improving the showroom they had visited. This presentation was worth $20 \%$ of the final grade. These two assessment designs allowed the teachers to observe students' preparation through their performance in the in-class activities, which is weighted in their final grade. By establishing explicit links between pre-class exposure, in-class activities, and assessment, teachers help students appreciate the importance of the pre-class foundation and the importance of think critically (Persky and McLaughlin, 2017). In addition, students can achieve the learning goal easier if pre-class exposure, in-class activities, and assessment are strongly connected (Ginns and Ellis, 2007).

\subsection{Activities}

\subsubsection{Concentrating on a Few Types of Flipping Activities}

As stated above, assigning too many types of in-class activity poses a challenge to the flipped classroom. Reducing the types of in-class activities can "allow students to become familiar with the active learning strategy and avoid the risk of students focusing on the process of the strategy rather than the learning related to content" (Gilboy et al., 2015, p. 112). Most of our teachers chose to reduce the types of in-class activities by implementing the flipped classroom partially. Among twenty-six courses, sixteen decided to have only 1 to 2 flipped classes, and eight planned for 3 to 6 flipped classes. The three courses that decided to flip all teaching classes (12 to 13) limited their types of in-class activities to group work, discussion, and presentation. The limited types of in-class activities can help students focus on the content of learning.

\subsubsection{Designing Activities to Focus on Application and Practice}

In some courses, doing experiments or applying knowledge to solve a problem formed the core of in-class activities. A marketing course had students' presentation of marketing strategies as its in-class activity. A science course centered its in-class activity on conducting experiments. A nursing course simulates a real-life clinical scenario in class. A course on electronic design required students to design electronic gadgets in class. The activities had the potential to deliver several advantages. First, the students were more attentive in class. Second, they were able to associate the abstract knowledge with things in the real-life and thus learning to put knowledge into real use. Therefore, students' knowledge was consolidated and they could achieve a higher degree of mastery. Third, these in-class activities have a clear connection with pre-class exposure.

\subsubsection{Planning Interactive and Engaging Activities}

As stated, increasing interaction is an important advantage of the flipped classroom approach. Interaction with students is also a way to catch students' attention to in-class activities. Most courses in the project adopted activities that encourage interaction between teacher and student and among students into their classroom. Group discussion, presentation, and group project were three common examples. Forming groups is an effective way to increase students' interaction (Gannod et al., 2008). Allen and Tanner (2005) suggests that group work can take away students' anxiety in participating large class discussion, both by trying out their ideas first among a smaller group of their peers and then by reporting to the class using the role of a spokesperson for a group (rather than voicing their own opinions). In all the four courses that 
consisted of more than 100 students, group work was an essential part of the flipped classes. One of the big courses further encouraged interaction by introducing a team competition into class. It employed different gaming software, including Bingo, Kahoot!, Badaboom, and constructed a real-time board game with iPad. The teacher of this course stated explicitly in the teaching profile that his class objective was to get students active in class, and the characteristic of his flipped class was an engaging and fun classroom. Besides, teachers also used various student response systems, such as uReply, a system that allows teachers improvising questions and students answering the questions by their mobile device, and Kahoot!, to deliver engaging interactions through the use of mobile technology.

Interaction is two-way. Continuously demanding students' response without giving feedback to them is not interaction. Indeed, students highly value constructive feedback from teachers. Nine courses emphasized on "giving feedback to students" in their course design, and four of them especially reserved in-class activity time for providing feedback to students' work.

\subsubsection{Arranging After-class Activities}

In addition, some teachers planned after-class activities to further consolidate their students' knowledge. In one course on science, planting on a rooftop was employed as an after-class activity. Some courses required their students to write a summary of in-class discussions or do calculation exercises after class. Other after-class activities included movie-watching, further discussions, post-class quizzes, or teachers providing feedback to students. Teachers' feedback on post-class learning is important too. By providing further feedback on students' areas of strengths and weaknesses, teachers give students the direction for more practices (Persky and McLaughlin, 2017).

\section{CONCLUSION}

This article examines the challenges of flipping the classroom demonstrated in previous literature through a framework according to the four key elements suggested by Brame. The four key elements are exposure, incentive, assess, and activities. Exposure is the materials provided for students to study before class. The quality of videos as exposure and students' need for assistance outside the classroom pose challenges to it. Incentives are provided for students to prepare for class. A score is a strong extrinsic incentive. The intrinsic incentive is on students' acceptance of the flipped classroom pedagogy. Challenges occur when students do not accept the pedagogy. The mechanism to assess students' understanding should be able to ensure students' preparation, but teachers find it difficult to do so. Activities in class should be designed to deepen students' understanding, enhance their skills, and promote interaction. However, the number of types of activities and the ability to engage students into activities pose challenges to the flipped classroom implementation.

Observing from the teaching profiles of the twenty-six teachers, we suggest eleven tips on flipped classroom design that would be able to meet these challenges. Regarding exposure, (1) the quality of videos can be ensured by adopting existing videos, especially those with proven quality, and a variety of media can also be used as pre-class exposure. Besides, (2) additional assistance such as guiding questions and online discussion support can help students' preparation. For incentive, (3) scoring pre-class tasks is a strong extrinsic incentive for students, and (4) teachers can facilitate students' intrinsic incentive by addressing the 
advantages and benefits of the flipped classroom pedagogy. In assessing students' preparation, three kinds of assessment can help teachers ensure that students are well-prepared: (5) assign pre-class tasks that cover pre-class exposure, (6) check students' preparation by in-class activities, and (7) design assignments that connect with pre-class and in-class activities. Regarding activity planning, (8) teachers should concentrate on a few types of activities or implementing flipped classroom partially. (9) In-class activities can be designed to focus on experiments or application of knowledge. (10) Interaction and student's engagement can be increased by different kinds of activities, and finally, (11) some extra activities can be arranged after class to further consolidate students' knowledge.

The preliminary research has various limitations. Firstly, the tips provided were concluded from observation of course design only. Their usefulness must be examined through observing the execution of those courses, which is also the focus in the next phase of our project. Future research assessing the effectiveness of the tips shall collect and examine two sets of data, including teachers' reflection on implementing their courses and students' opinion towards the flipped class they attended. Second, as mentioned in the introduction, teachers' willingness to participate, school support and technical support are also vital in the implementation of the flipped classroom. Due to the scope of this article, the challenges in these aspects were not assessed thoroughly. Further investigation in this research project would shed light on these aspects.

\section{ACKNOWLEDGMENT}

The authors would like to thank Ms. Ivy Lu Ming, Ms. Man Tsang Yuen Man, and Mr. Bernado Wong Yuk Wang from the Chinese University of Hong Kong; Dr. Crusher Wong and Ms. Angel Lu from City University of Hong Kong; Dr. Cheung Ka Lun and Ms. Rebecca Lin Xiaoying from the Education University of Hong Kong; Dr. Theresa Kwong and Dr. Isaac Chan Chi Fai from Hong Kong Baptist University; and Dr. Kevin Chan, Mr. George Cheung and Mr. Cypher $\mathrm{Au}$ Yeung from the Hong Kong Polytechnic University for their efforts in recruiting the teachers and collecting the teaching profiles. The authors also wish to thank the teachers for their contribution of completing the teaching profiles. This paper is part of the project "Effective Implementation of the Flipped Classroom Approach in Hong Kong Higher Education for Enhanced Learning Outcomes", which has been supported by the University Grants Committee of Hong Kong. Part of this work was presented at the International Conference on Educational Technologies 2019.

\section{REFERENCES}

Allen, D. and Tanner, K. 2005. Infusing active learning into the large-enrollment biology class: seven strategies, from the simple to complex. Cell Biology Education, 4, 262-268.

Abeysekera, L. and Dawson, P. 2014. Motivation and cognitive load in the flipped classroom: definition, rationale and a call for research. Higher Education Research \& Development, 34 (1), 1-14.

Akçayır, G. and Akçayır, M. 2018. The flipped classroom: a review of its advantages and challenges. Computer and Education, 126, 334-345. 
Baker, J. W. 2000. The "classroom flip": using web course management tools to become the guide on the side. Selected Papers from the $11^{\text {th }}$ International Conference on College Teaching and Learning (pp. 9-17). Chambers, J. ed. Jacksonville: Center for the Advancement of Teaching and Learning, Florida Community College.

Bhagat, K. K. et al. 2016. The impact of the flipped classroom on mathematics concept learning in high school. Educational Technology \& Society, 19(3), 134-142.

Brame, C. 2013. Flipping the classroom. Retrieved [7 Nov. 18] from http://cft.vanderbilt.edu/guides-subpages/flipping-the-classroom/.

Chen, K.-S. et al. 2018. Academic outcomes of flipped classroom learning: a meta-analysis. Medical Education, 52(9), 910-924.

Chen, L. et al. 2015. Students' perspectives of using cooperative learning in a flipped statistics classroom. Australasian Journal of Educational Technology, 31(6), 621-640.

Chen, Y. et al. 2014. Is FLIP enough? Or should we use the FLIPPED model instead? Computers \& Education, 79, 16-27.

Cheng, X. et al. 2017. The "Flipped Classroom" approach: stimulating positive learning attitudes and improving mastery of histology among medical students. Anatomical Science Education, 10(4), 317-327.

Davies, R. S. et al. 2013. Flipping the classroom and instructional technology integration in a college-level information systems spreadsheet course. Educational Technology Research and Development, 61(4), 563-580.

Fautch, J. M. 2015. The flipped classroom for teaching organic chemistry in small classes: Is it effective? Chemistry Education: Research and Practice, 16(1), 179-186.

Gannod, G. C. et al. 2008. Using the inverted classroom to teach software engineering. In ICSE '08: Proceedings of the 30th International Conference on Software Engineering (pp. 777-786). ACM, New York, NY.

Gilboy, M. B. et al. 2015. Enhancing student engagement using the flipped classroom. Journal of Nutrition Education and Behavior, 47(1), 109-114.

Ginns, P. and Ellis, R. 2007. Quality in blended learning: exploring the relationships between on-line and face-to-face teaching and learning. Internet and Higher Education, 10(1), 53-64.

Gouia, R. and Gunn, C. 2016. Making mathematics meaningful for freshmen students: investigating students' preferences of pre-class videos. Research and Practice in Technology Enhanced Learning, 11(2). DOI 10.1186/s41039-015-0026-9

Herreid, C. F. and Schiller, N. A. 2013. Case studies and the flipped Classroom. Journal of College Science Teaching, 42(5), 62-66.

Khanova, J. et al. 2015. Student experiences across multiple flipped courses in a single curriculum. Medical Education, 49(10), 1038-1048.

Kim, M. K. et al. 2014. The experience of three flipped classrooms in an urban university: an exploration of design principles. Internet and Higher Education, 22, 37-50.

Koh, K. H. et al. 2018. Experience: Learner Analytics Data Quality for an eTextbook System. ACM Journal of Data and Information Quality, 9(2), 10:1-10:10.

Lage, M. J. et al. 2000. Inverting the classroom: a gateway to creating an inclusive learning environment. The Journal of Economic Education, 31(1), 30-43.

Mason G. S. et al. 2013. Comparing the effectiveness of an inverted classroom to a traditional classroom in an upper-division engineering course. IEEE Transactions on Education, 56(4), 430-435.

McGivney-Burelle, J. and Xue, F. 2013. Flipping calculus. PRIMUS. 23(5): 477-486.

Missildine, K. et al. 2013. Flipping the classroom to improve student performance and satisfaction. Journal of Nursing Education, 52(10), 597-599. 
IADIS International Journal on WWW/Internet

Moraros, J. et al. 2015. Flipping for success: evaluating the effectiveness of a novel teaching approach in a graduate level setting. BMC Medical Education, 15: 27. DOI 10.1186/s12909-015-0317-2

Persky, A. M. and McLaughlin, J. E. 2017. The flipped classroom - from theory to practice in health professional education. American Journal of Pharmaceutical Education, 81(6), 1-11.

Prince, M. 2004. Does active learning Work? A review of the research. Journal of Engineering Education, 93, 223-231.

Sams, A. 2011. There is no such thing as THE Flipped Class (5 OCT- 2011) http://chemicalsams.blogspot.com/2011/10/there-is-no-such-thing-as-flipped-class.html (retrieved on 3 Oct 2018)

Snowden, K. E. 2012. Teacher perceptions of the flipped classroom: using video lectures online to replace traditional in-class lectures. Master's thesis, University of North Texas. Retrieved June 25, 2019, from https://www.learntechlib.org/p/119238/.

Strayer, J. 2007. The Effects of the Classroom Flip on the Learning Environment: A Comparison of Learning Activity in a Traditional Classroom And a Flip Classroom that Used an Intelligent Tutoring System (Doctoral Dissertation). Retrieved from etd.ohiolink.edu/ (Accession No. osu1189523914)

Thai, N. T. T. et al. 2017. The impact of a flipped classroom design on learning performance in higher education: look for the best 'blend' of lectures and guiding questions with feedback. Computers \& Education, 107, 113-126.

Wanner, T. and Palmer, E. 2015. Personalising learning: exploring student and teacher perceptions about flexible learning and assessment in a flipped university course. Computers \& Education, 88, 354-369.

White, P. J. et al. 2017. Student engagement with a flipped classroom teaching design affects pharmacology examination performance in a manner dependent on question type. American Journal of Pharmaceutical Education, 81(9), 10-23.

\section{APPENDIX: SAMPLE OF TEACHING PROFILE}

Flipped Classroom in Higher Education Project

Teaching Trials $\left(1^{\text {st }}\right.$ round; $1^{\text {st }}$ semester, 2018/19)

\section{Profile}

\section{Course Information}

\begin{tabular}{|l|l|}
\hline Course name & \\
\hline Course code & \\
\hline Instructor name & \\
\hline Classroom & \\
\hline $\begin{array}{l}\text { Lecture/ Tutorial } \\
\text { (Time/Day) }\end{array}$ & \\
\hline Class size & \\
\hline
\end{tabular}




\section{Course Design}

Briefly illustrate how the flipped classroom approach is incorporated into the course design

\begin{tabular}{|l|l|}
\hline $\begin{array}{l}\text { Objectives of using the } \\
\text { flipped classroom approach } \\
\text { in this course }\end{array}$ & \\
\hline $\begin{array}{l}\text { Number of classes that use } \\
\text { the flipped mode }\end{array}$ & \\
\hline Activities before class & \\
\hline $\begin{array}{l}\text { Ways to encourage students } \\
\text { to complete the above } \\
\text { activities }\end{array}$ & \\
\hline Activities during class & \\
\hline Activities after class & \\
\hline Assessment design & \\
\hline Others & \\
\hline
\end{tabular}

